\title{
Facile synthesis of highly porous nano-scale gadolinium -MPCA frameworks for bioimaging applications
}

\author{
Ravneet Kaur ${ }^{1}$, Kanwalpreet Kaur ${ }^{1}$, Heena Sammi ${ }^{1}$, Mohit Rawat ${ }^{1}$, Gurjinder $\operatorname{Singh}^{2}$ and \\ Deepak Kukkar ${ }^{*}$ \\ ${ }^{1}$ Department of Nanotechnology \\ ${ }^{2}$ Department of Electronics Engineering \\ Sri Guru Granth Sahib World University, Fatehgarh Sahib - 140406, Punjab, India. \\ *Email: deepakukkar@gmail.com
}

In recent years hybrid, porous co-ordination polymers called Nanoscale Metal-organic frameworks (NMOFs) have emerged as sophisticated materials for analytical applications owing to their infinitesimal tunable characteristics that result from the limitless choice of metals and organic bridging ligands [1-2]. NMOFs are constructed using two components: (a) Metal ions, and (b) Organic Linkers which are joined using strong co-ordination bonds [3-5].

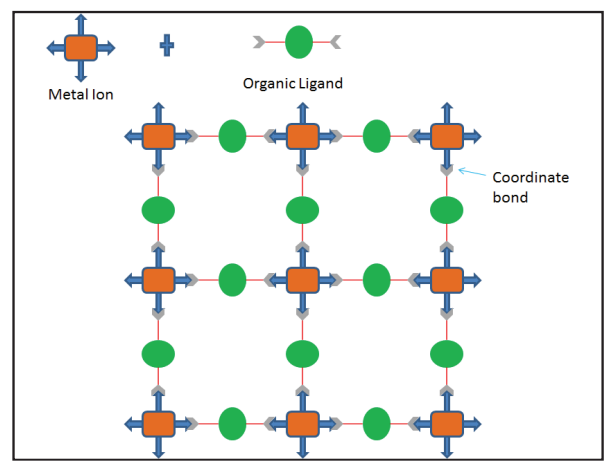

Figure 1: Schematic representation showing coordination linkage between metal ions and organic ligand to form the NMOFs

Figure 1 shows a schematic for NMOF synthesis using coordination between the metal ion and the linker. Majority of the study reports highly toxic and reactive organic linker for the synthesis of NMOFs. To overcome this predicament, present study was focused on preparation of highly biocompatible NMOFs using 1-methyl-2 pyrrole carboxylic acid (MPCA) as the organic linker. Metal salt and linker were added separately into previously prepared microemulsion of 1- Hexanol, Heptane and CTAB. Optical characterization of the particles revealed a sharp band at $260 \mathrm{~nm}$, indicating the formation of NMOFs. The synthesis of the particles was affirmed by FTIR spectroscopy which showed broadening of characteristic $-\mathrm{C}=\mathrm{O}-$ stretching vibration and increase in the $-\mathrm{C}=\mathrm{C}-/-\mathrm{C}=\mathrm{N}$ - stretching observed in MPCA at 1694 and $1465 \mathrm{~cm}^{-1}$ as evident from figure 2 .

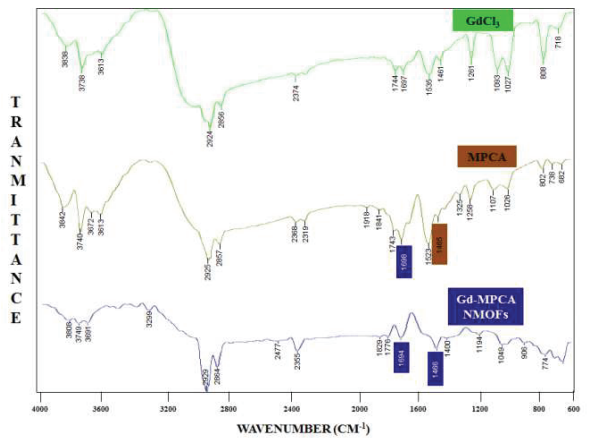

Figure 2: FTIR spectra of (a) $\mathrm{GdCl}_{3} \cdot 6 \mathrm{H}_{2} \mathrm{O}$, (b) MPCA \& (c) Gd-MPCA NMOFs. Broadening of characteristic $-\mathrm{C}=\mathrm{O}-$ stretching vibration and increase in the $-\mathrm{C}=\mathrm{C}-/-\mathrm{C}=\mathrm{N}-$ stretching was observed in NMOF particles as compared to MPCA at 1694 and $1465 \mathrm{~cm}^{-1}$ and evident from the highlighted boxes

The average diameter of the particles determined from particle size analyzer was $232.4 \mathrm{~nm}$ with a poly dispersity index of 0.006 . Current study thus explores the synthesis of biocompatible NMOFs for bio imaging applications.

\section{References}

1. Cui,Y.; Yue, Y.; Qian, G.; Chen, B. Chem. Rev. 112, (2012) 1126-1162.

2. Cui,Y.; Chen, B.; Qian, G. Coord. Chem. Rev. 273-274 (2014) 76-86.

3. Furukawa, H.; Cordova, K. E.; O'Keeffe, M.; Yaghi, O. M. Science. 341 (2013) 1230444.

4. Xuan, W.; Zhu, C.; Liu, Y.; Cui, Y. Chem. Soc. Rev. 41 (2012) 1677-1695.

5. Liu, D.; Lu, K.; Poon, C.; Lin, W. Inorg. Chem. 53 (2014) 1916-1924. 